\title{
Algısal Homofili ve Marka-Fenomen Uyumu Perspektifinden Sosyal Medya Fenomenlerinin Marka Tutumuna Etkisi
}

\section{Effects of Social Media Influencers on Brand Attitude From The Perspective Of Brand-Influencer Compatibility And Perceived Homophily}

Fatma Özge Baruönü a,*

${ }^{a}$ Dr. Öğr. Üyesi, Doğuş Üniversitesi, İktisadi ve İdari Bilimler Fakültesi, Uluslararası Ticaret ve İşletmecilik Bölümü, İstanbul /Türkiye. ORCID: 0000-0001-5533-775X

\section{MAKALE BİLGISII}

\section{Makale Geçmişi:}

Başvuru tarihi: 04 Temmuz 2020

Düzeltme tarihi: 09 Ocak 2021

Kabul tarihi: 13 Ocak 2021

Anahtar Kelimeler:
Fenomen
Sosyal Medya
Algisal Homofili
Marka

ÖZ

Sosyal medya reklamcılı̆̆ının yeni bir biçimi olan fenomen pazarlaması son yıllarda markalar tarafından sıklıkla kullanılmaktadır. Bu çalışmada, sosyal medya fenomenlerinin destekledikleri markalarla ilgili olarak pozitif tüketici tutumu ve satın alma niyeti oluşturmalarında etkili faktörleri ortaya koyan kavramsal bir model önerilmiş ve ampirik bir çalışma ile test edilmiştir. 2020 y1l Mayıs ayı içerisinde, en az bir sosyal medya fenomenini takip eden 124 katılımcıyla, çevrimiçi anket yapılmıştır. Araştırmanın sonuçları, tüketici tutumlarını ve satın alma niyetlerini etkilemede sosyal medya fenomenlerinin pozitif etkisini ortaya koymakta, ayrıca pazarlama yöneticilerinin markalarını desteklemek için sosyal medya fenomenlerini belirlerken, fenomen çekiciliğini, güvenilirliğini ve fenomen-marka uyumunu ve fenomen hedef kitle benzerliğini de (algısal homofili) dikkate almaları gerektiğinin altını çizmektedir.

Marka-Fenomen Uyumu

\section{ART ICLE INFO}

Article history:

Received 04 July 2020

Received in revised form July 09 Ocak 2021 Accepted 13 January 2021

\section{Keywords:}

Influencer

Social media

Perceived homophily

Brand

Brand-Influencer Compatibility

\section{A B S T R A C T}

Infleuncer marketing, a new form of social media advertising, has been frequently by brands in recent years.In this study, a conceptual model that demonstrates the effective factors in creating a positive consumer attitude and purchasing intention regarding the brands supported by social media influencers is proposed and tested with an empirical study. In May 2020, an online survey was conducted with 124 participants following at least one social media influencer.The findings reveal the positive impact of influencer in affecting consumer attitudes and purchasing intentions. It specifically underlines that marketing managers should consider the attractiveness and reliability of influencer beside influencer-brand compatibility, and influencer-target population similarity when choosing the influencer to support their brand.

\section{Giriş}

Geleneksel reklamcilıkta, bir reklam stratejisi olarak sıklıkla yer alan ünlü kullanımının, markanın ikna etme gücünü artırdığı bilinmektedir. Ürün veya hizmetin ünlü kişiler tarafından onaylanması güvenilirlik ve itibar açısından ürüne katma değer sağlamaktadır (Bergkvist vd., 2016; Amos vd., 2008). Bunun nedeni tüketicilerin, ünlü medya kişiliklerini takip etmeyi, yaşam tarzlarını, ne yediklerini, nereye gittiklerini, ne giydiklerini keşfetmeyi sevmesinden kaynaklanmaktadır. Hatta tüketicilerin alışveriş davranışlarında bile ünlüleri taklit etme eğilimi gösterdiği bilinmektedir (Reeves vd., 2012).

Sosyal medyanın geleneksel medyanın payından büyük bir dilim çaldığı günümüzde, Youtube yıldızlarının Holywood yıldızlarından daha popüler olduğu bir dünyada

\footnotetext{
*Sorumlu yazar/Corresponding author.

e-posta: obaruonu@dogus.edu.tr
} 
yaşamaktayız, tıpkı Justin Bieber'in Youtube'dan doğup dünyanın en ünlü şarkıcılarından olması örneğinde olduğu gibi (Baruönü, 2019). Özellikle Youtuber olarak ifade edilen YouTube kanal yöneticileri ve Instagram fenomenleri sosyal medyanın ünlüleri olarak karşımıza çıkmakta ve özellikle $Y$ ve $Z$ kuşağı için sanal dünyada kanaat lideri görevini üstlenmektedir. Sosyal medya fenomenleri (influencer), sosyal medyanın fikir liderleri olarak tanımlanır ve "bir veya birkaç alanda güvenilir destekçiler" olarak kabul edilirler (DeVeirman vd., 2017:798). Sosyal medyada büyük sosyal takipçi ağları oluşturarak, Youtube, Instagram ve Twitter gibi mecralarda düzenli içerik üreten, bu kişiler, $Y$ ve $Z$ kuşağı tarafından yakından takip edilmektedir, hatta birçok tiyatrocu, oyuncu, şarkıcı gibi medyatik isimden daha fazla popülariteye sahip olmuş durumdadırlar (Patel, 2019). Senft (2008), bu kişileri "mikro ünlüler" olarak adlandırmıştır. Ünlülerin aksine, sosyal medya fenomenleri kişisel hayatlarını paylaştıkları ve doğrudan takipçileriyle etkileşime girdikleri için takipçileri ile daha kolay ilişki kurabilmektedir. Dolayısıyla, onların erişilebilir, inandırıcı ve samimi olduğu düşünülmektedir. Twitter takipçileri üzerinde yapılan bir çalışma bir fenomenin bir marka ile ilgili tweet atmasının kullanıcıların \% 40'ının o ürünü satın almasına sebep olduğunu göstermiştir (Karp, 2016).

Sosyal medya reklamcılığının yeni bir biçimi olan fenomen pazarlaması son yıllarda popülerlik kazanmıştır (Linqia, 2018). Pazarlamacıların \% 39'unun fenomen pazarlama için bütçelerini artırdığını ve \%19'unun kampanya başına 100.000 USD'den fazla harcama yaptığı bilinmektedir (Bevilacqua ve Del Giudice, 2018). Bu çalışma, fenomen pazarlamasının marka tutumu üzerinde etkili olması için, fenomen özellikleri, tüketici tutumu ve marka tutumuna dair ilişkileri birlikte ele alarak, ampirik bulgularla pazarlama profesyonellerine fenomen seçiminde yol göstermeyi amaçlamaktadır. Çalışmanın ilk kısmında literatür taraması ve teorik çerçeve sunulmuş, daha sonra araştırma metodolojisi ve bulgulara yer verilmiştir. Son bölümde ise çalışma bulgularının teorik ve pratikte ne şekilde kullanılabileceği ve gelecek araştırma önerileri tartışılmıştır.

\section{Literatür Taraması}

\subsection{Fenomen ve Marka Onay1}

Katz ve Lazarsfeld (1955) kanaat önderlerini, "yakın çevrede bulunan kişileri etkileme gücüne sahip bireyler" olarak tanımlamaktadır. Yazarların geliştirdikleri "çift aşamalı akış teorisine" göre, tutum ve davranışların değiştirilmesinde, kitle iletişim araçları tarafından yayılan mesajlar fikir liderleri tarafından süzgeçten geçirilerek daha büyük gruplar arasında yayılır. Teori, kişilerarası iletişimin, kitlesel iletişim tekniklerine göre daha güçlü olduğunu vurgulamaktadır (Weimann, 1994).

Literatürde yer alan pek çok çalışma, fenomenlerin yeni segmentleri hedeflemede (Crutchfield, 2010), olumlu ürün değerlendirmeleri kazanmada (Dean ve Biswas, 2001), marka bilinirliğini ve sadakatini arttırmada (Miller ve Laczniak, 2011) kullanıldığını göstermektedir. İlgi alanları ve takipçi sayısı fenomen seçmede markalara rehber olmaktadır (Swant, 2016). Ancak kimi durumlarda markaların özel hedeflerine bağlı olarak, kendilerine yeni hedef kitle oluşturmak, yeni pazarlara ulaşmak için sektörel olarak konuyla hiç ilgisi olmayan ancak milyonlarca takipçisi olan kişileri tercih ettiği de görülmektedir (Curalate, 2016). Sosyal medya fenomenlerinin, sıradan ya da ücret karşılığı reklamlarda kullanılan ünlülerden daha güvenilir ve özgün olduğu varsayımına dayanarak, bazı reklam verenlerin marka ile sosyal medya fenomeni arasındaki uyumsuzluğun çok önemli olmadığını ifade etmektedir (Djafarova ve Rushworth, 2017). Ancak Volvo'nun daha önce otomobillerle ilgisi olmayan ancak çok sayıda takipçisi olan Chriselle Lim ile çalışması medyada hem markaya hem de fenomene karşı eleştiriler ile dönmüştür (Curalate, 2016). Sosyal medya fenomenlerini inceleyen çalışmalar, fenomenin ikna-bilgi modelini kullandığı durumlarda takipçiler bu ikna çabasını hissederse gönderileri paylaşmaktan uzak durduğunu göstermektedir (Evans vd., 2017).

Fenomen kullanımının etkisi ölçülürken üç temel faktör ele alınmaktadır. Bunlar, fenomenin özellikleri (Çekicilik, güvenilirlik, uzmanlık), tüketicilerin özellikleri (demografikleri ve kişilik) ve pazarlama çabasına ait (marka-ünlü uyumu, iletişim kanalı, ürün kategorisi vs.) özelliklerdir (Erdoğan, 1999).

Fenomenlerin tüketiciyi etkileyebilmesi konusundaki düşünceler iki genel teoriye dayanmaktadır; Kaynak güvenilirlik modeli ve kaynak çekicilik modeli. Kaynak güvenilirlik modeli, kaynak etkisi teorisinden yararlanır ve bir iletişim kaynağının çeşitli özelliklerinin ve özelliklerinin mesaj üzerinde etki yarattığını öne sürer (Hovland vd.,1953). Kaynak güvenilirlik modeli, güvenilirliği, çekiciliği ve uzmanlığı güvenilirliğin temel boyutları olarak tanımlamaktadır (Amos vd., 2008; Ohanian, 1990) Hovland vd. (1953) uzmanlığı "bir iletişimcinin geçerli bir iddianın kaynağı olarak algılanma derecesi", güven duygusunu ise "iletişimcinin en geçerli gördüğü iddiaları iletme niyetine güven derecesi" olarak tanımlamıştır.

Kaynak çekiciliği modelinin kökenleri ise sosyal ve psikolojik araştırmalarda kaynaklanmaktadır ve McGuire'in "kaynak değerlik" modelinin bir bileşenidir (McGuire, 1985). Çekicilik modeli, bir mesajın etkililiğinin kaynağın katılımcılara "aşinalık", "benzerlik", ve "çekiciliğine" bağlı olduğunu iddia etmektedir. Söz konusu çekicilik sadece fiziksel özelliklerin çekiciliğini kastetmemektedir. İşlevsel hale getirilmiş fiziksel çekicilik (Kahle ve Homer, 1985), şıklık (Mills ve Aronson, 1965), cinsellik (Steadman, 1969) kavramları da farklı araştırmacılar tarafından çekicilik alt boyutları olarak incelenmiştir. Sosyal medya fenomeninin çekiciliği, sosyal medya fenomeninin onayladığı tüm markaları olumlu bir şekilde görmeye yönlendirebilir. $\mathrm{Bu}$ nedenle, etkili olabilmek için, marka onayı, markayla uyumlu, takdir edilen veya popüler olan bir fenomenden gelmelidir. Dolayısıyla aşağıda yer alan hipotezler ortaya konmuştur.

H1a: Sosyal medya fenomeninin fiziksel çekiciliği markaya karşı olan tutumu pozitif etkiler

H1b: Sosyal medya fenomeninin fiziksel çekiciliği markayı satın alma niyetini pozitif etkiler

Kaynak güvenilirliğinin ikinci boyutu olan güvenilirlik, alıcıların bir kaynağı dürüst, samimi veya doğru olarak 
algılamasıyla ilgilidir (Giffin, 1967). Sosyal fenomenler kendi alanlarında çokça fikirleri sorulan, görüşleri alınan ve içinde bulundukları gruptaki diğer kişilere nazaran kendilerine daha sık başvurulan kişilerdir (Lazarsfeld ve Merton, 1954). Çok sayıda çalışma, güvenilirliğin tutum değişikliği üzerindeki etkisini desteklemektedir. Miller ve Baseheart (1969) kaynak güvenilirliğinin iletişimin ikna edilebilirliği üzerindeki etkisini araştırmıştır. Sonuçlar, iletişimcinin son derece güvenilir olduğu düşünüldüğünde, iletişimin daha etkili olduğunu göstermiştir. Buna ek olarak, güvenilirlik, katılımcının kaynakla algılanan benzerliği, kaynağın uzmanlık düzeyi ve kaynağın çekiciliği ile yüksek derecede ilişkili bulunmuştur (Friedman vd.,1979). Twitter kullanıcıları ile yapılan bir çalışma, kullanıcıların fenomenlere karşı arkadaşlarına duyduğu seviyede güven duyduklarını ortaya koymuştur (Swant, 2016). Bu nedenle fenomenlere duyulan güven markaya duyulan güvene yansımaktadır. Sosyal medya fenomenlerinin normal onaylayıc1lardan daha güvenilir ve özgün olduğu varsayımına dayanarak (Djafarova ve Rushworth, 2017) aşağıda yer alan hipotezler önerilmiştir;

H2a:Sosyal medya fenomenlerinin güvenilirliği markaya karşı olan tutumu pozitif etkiler

$\mathrm{H} 2 \mathrm{~b}$ :Sosyal medya fenomenlerinin güvenilirliği markayı satın alma niyetini pozitif etkiler

Uzmanlık, Hovland ve diğerleri (1953) tarafindan tanımlanan kaynak güvenilirliğinin sonuncu boyutudur. İkna edici iletişimde kaynak uzmanlığını araştıran araştırmalar genellikle kaynağın algılanan uzmanlığının tutum değişikliği üzerinde olumlu bir etkiye sahip olduğunu göstermektedir (Horai vd., 1974; Maddux ve Rogers, 1980; Mills ve Harvey, 1972) Örneğin Crisci ve Kassinove (1973), iletişimci uzmanlığının algılanan seviyesinin "Dr." ünvanı kullanıldığında arttığını göstermiştir. Dolayısıyla $\mathrm{H} 3 \mathrm{a}$ ve $\mathrm{H} 3 \mathrm{~b}$ hipotezlerine yer verilmiştir.

H3a:Sosyal medya fenomeninin uzmanlığı markaya karş1 olan tutumu pozitif etkiler

H3b:Sosyal medya fenomeninin uzmanlığı markayı satın alma niyetini pozitif etkiler

\subsection{Marka-Fenomen ve Fenomen-Tüketici Uyumu}

Tran vd. arkadaşları (2019) fenomenlerin tüketicileri olumlu tutum ve davranışsal tepkilere sevketmesini parasosyal ilişki teorisi kapsamında açıklamaya çalışmıştır. $\mathrm{Bu}$ yaklaşım, ünlülerin sosyokültürel etkilerine ve tüketici algılarını fenomen psikolojik süreçlere odaklanmaktadır. Parasosyal ilişki bireylerin, medyadaki ünlülerle kurduğu tek taraflı kişiler arası ilişkileri ifade etmektedir (Sakib vd., 2019). Tüketicilerin parasosyal ilişkiler geliştirdiği ünlülerin önerdiği ürünlerden daha çok etkilenmeleri beklenmektedir (Chung ve Cho, 2017;Tran ve Strutton, 2014). Yaygın olarak "fandom" olarak tanımlanan parasosyal ilişkiler, bireysel tüketicilerin bireysel ünlülerle derin bağlantı duyguları yaşamasına izin vermektedir (Spitzberg ve Cupach, 2008). Parasosyal ilişkiler içinde, bireyler genellikle ünlü insanları davranışsal rehberlik için baktıkları, taklit ettikleri ve aslında takip ettikleri varlıklar olarak görmektedirler (Horton ve Wohl, 1956). Sosyal medyanın, beğenme, soru sorma, yorum yazma gibi özellikleriyle tüketici-fenomen iletişimini çift yönlü hale getirmesi parasosyal ilişkilere geleneksel medyadan daha farklı bir anlam yüklemektedir. Tamamen tek yönlü olmaktan uzaklaşan ilişki asimetrik olmakla birlikte, markadan tüketiciye, fenomenden tüketiciye doğru uzanabilmektedir.

Algısal homofili, "karşılıklı iki bireyin genellikle demografik özellikleri olmak üzere birbirleriyle ne kadar uyumlu olduğudur" ancak bununla birlikte homofili demografik özellikler ile birlikte, değerler, tercihler, yaşam tarzı gibi değişkenlerdeki algısal benzerliklerle de baş göstermektedir (Everett ve Bhowmik, 1971: 523-538). Homofili teorisi ilk kez Lazarsfeld ve Merton (1954) tarafından ortaya atılmış ve pek çok tüketici davranışı çalışmasında kişilerarası iletişimi açıklamak da kullanılmıştır (Örs, 2018:197). Çalışmalar tüketicilerin kendilerine benzer-yakın kaynaklardan tavsiye aldıklarını ve bazı durumlarda uzman kaynaklara nazaran homofilik kaynakların tavsiye almada daha iyi çalıştığını göstermektedir (Gilly vd., 1998). Sosyal medya fenomenitüketici ilişkisinde etkili faktörleri inceleyen Örs (2018:201) algısal homofilinin bu ilişkide de etkili olduğunu ortaya koymuştur. Takipçilerin fenomen ile kendisini benzetmesi, onu kendine yakın bulması fenomene duyduğu güveni ve dolayısıyla markaya karşı pozitif tutumu artıracaktır. Bu nedenle $\mathrm{H} 4 \mathrm{a}$ ve $\mathrm{H} 4 \mathrm{~b}$ hipotezleri önerilmiştir.

H4a Algisal homofili marka tutumunu pozitif etkilemektedir

H4b Algısal homofili fenomenin güvenilirliğini pozitif etkilemektedir

Ünlüyle, marka arasındaki eşleşme prensibine dayanarak (eşleştirme hipotezi) fenomen kişi seçerken kişinin markayı tanımlayan, kişiliği marka kişiliğiyle örtüşen bir kimse olması beklenir (Bergkvist vd., 2016, Kamins, 1990; Choi ve Rifon, 2012; Fleck vd., 2012). Bu eşleştirmelerin başarısı pazarlamacıların "doğru uyumu" sağlamak amaciyla "doğru fenomenleri” stratejik olarak tanımlamasına bağlıdır (Kamins ve Gupta, 1994). Mishra, Roy ve Bailey (2015) bu uyarlamayı desteklemek için sosyal uyum teorisi ve atıf teorilerinden yararlanmışlardır. Sosyal uyum teorisi bağlamında, ünlülerin kişilikleri tanıtılan marka imajına uygun görünüyorsa, takipçilerin onları etkili bir bilgi kaynağı olarak algılanacağı öngörüsüne dayanmaktadır (Kamins, 1990; Mishra vd., 2015). Örneğin kozmetik ürünlerin tanıtımı için fiziksel olarak çekici kişiler tercih edilmektedir. İlişkilendirme teorisi ise fenomen ile markanın gerçek hayatta da ilişkilendirilmesi esasından yola çıkmaktadır (Mishra vd., 2015). Tüketiciler, fenomenin gerçek hayatta da markanın bir kullanıcısı olduğuna inanma, bir reklam sözleşmesi nedeniyle değil, beğendikleri veya kullandıkları için söz konusu markayı tanıttıklarını düşünmelidirler (Koernig ve Boyd, 2009). Bu nedenle bir sporcuyu, şeker, cips ve atıştırmalık değil de vitamin ya da besin desteği ürünleri tanıtımında onaylayıcı olarak kullanmak daha popülerdir. Torres ve diğerlerinin çalışması (2019) marka uyumunun, doğrudan ve dolaylı olarak, markaya yönelik tutumu ve satın alma niyetini etkilediğini ortaya koymuştur. Breves ve diğerlerinin (2019) araştırmasında marka-fenomen uyumunun yüksek olduğu durumlarda marka tutumu ve satın alma niyetinin 
arttı̆̆ı gözlemlenmiştir. Dolayısıyla, fenomen ve marka uyumunun artmasının markaya karşı olan tutumu ve satın alma niyetini pozitif etkileyeceği beklenmektedir. Dolayısıyla aşağıdaki hipotezlere yer verilmiştir.

H5a: Sosyal medya fenomeniyle marka arasındaki uyum markaya karşı olan tutumu pozitif etkiler

H5b: Sosyal medya fenomeniyle marka arasındaki uyum markayı satın alma niyetini pozitif etkiler

Son olarak, gerekçeli aksiyonlar teoremine (TRA) dayanarak tutumların davranışlar üzerindeki etkisini ölçmek için aşağıdaki hipoteze yer verilmiştir:

H6: Marka tutumunun marka satın alma niyeti üzerinde pozitif etkisi vardir.

Araştırmanın grafiksel modeli Şekil 1'de gösterilmiştir.

Şekil 1. Araştırma Modeli

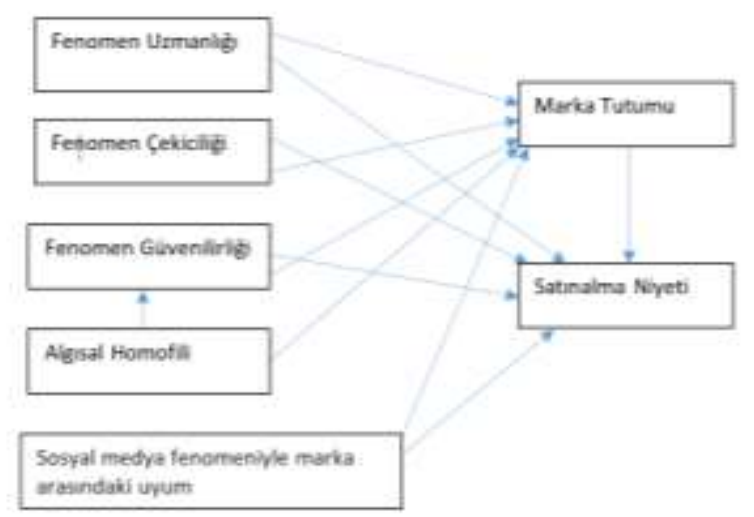

\section{Yöntem ve Uygulama}

Araştırmanın amacı, günümüzde önemli bir dijital pazarlama aracı olarak görülen sosyal medyada marka fenomenlerinin, tüketicinin marka tutumunu ve satın alma niyetini etkilemedeki rolünü ortaya koymaktır. Bu amaçla, fenomenin güvenilirliği, çekiciliği, uzmanlığ fenomene karşı homofili algısı ve marka-fenomen uyumu değişkenleri çerçevesinde konu ele alınmıştır.

Üniversite öğrencilerinin kimliklerini ve görünümlerini geliştirmek için genellikle ünlülere güvendikleri bilinmektedir (Banister ve Cocker, 2014). Bu nedenle araştırmanın örneklemini 18-30 yaş arası en az bir fenomeni takip eden 124 lisans/ yüksek lisans öğrencisi oluşturmuştur. Araştırmanın örnek boyutu hesaplanırken Tabachnich ve Fiddel'in (2001) bağımlı değişken sayısını gözönünde bulundurarak öne sürdüğü hesaplama $(\mathrm{N}>50+8 \mathrm{~m})$ kullanılmıştır. Bu formüle göre ulaşılması gereken yeterli sayı 106'dır. çalışmada ulaşılan 124 örneklem sayısı yeterli görülmektedir. Örnekleme metodu olarak kolayda örnekleme seçilmiştir. Anket online olarak dağıtılmış ve sonuçlar 1 ay içerisinde toplanmıştır. Filtre soru olarak bir sosyal medya fenomenini takip edip etmedikleri sorulmuştur. 30 kişi ile ön test yapılmış ve soruların anlaşılırlığı test edilmiştir. Sosyal medyada bir fenomeni takip eden kişiler onu bir markayla özdeşleştirmiş ve ilgili marka için sorunları cevaplamışlardır. Tüm sorular 5'li Likert ölçek ile sorulmuştur (1- kesinlikle katılmıyorum, 5- kesinlikle katılıyorum). Araştırmanın verileri AMOS paket programı kullanılarak sırasıyla onaylayıcı faktör analizine ve yapısal eşitlik modeli yol analizine tabi tutulmuştur.

Kaynak güvenilirliğini üç alt boyutu olan çekicilik, güvenilirlik ve uzmanlık değişkenleri Ohanian'ın (1990) ve Nguyen ve diğerlerinin (2015) ölçeğinden uyarlanmıştır. Çekicilik 4, güvenilirlik ve uzmanlık üçer soru ile sorulmuştur. Fenomen ile markanın uyumu tek soru ile Till ve Busler'in (2000) ölçeğinden adapte edilmiştir. Marka tutumu Colliander ve Dahlén's (2011) ölçeği ve marka satın alma niyeti Chai, Malhotra ve Alpert'in (2015) ölçeği ile ölçülmüştür. Algısal homofobi ise Wolfinbarger ve Gilly’nin (1993) tek soruluk ölçeğiyle ölçülmüştür.

Araştırmada normallik varsayımını test etmek için öncelikle çarpıklık ve basıklık değerlerine bakılmıştır. Analiz sonucunda çarpıklık değerinin $-1,122$ ile 0,605 değerleri arasında ve basıklık değerinin $-1,085$ ile 1,023 aralığında yer aldığı tespit edilerek verilerin normal dağılım gösterdiğ görülmüştür (Tabachnick ve Fidell, 2001) . Bunun yanında veride çoklu bağıntı probleminin olup olmadığını test etmek amacıyla araştırmanın tüm bağımsız değişkenlerinin Tolerans ve VIF değerlerine bakılmış (Sipahi, 2010) ve yapılan analiz sonucunda Tolerans değerinin 0.1 'in ve VIF değerlerinin 10'nun altında çıkması sebebiyle çoklu bağıntı problemi olmadığı tespit edilmişti

\section{Bulgular}

\subsection{Demografik Bulgular}

Katılımcılar, 64 kadın 60 erkek olmak üzere 124 kişiden oluşmaktadır. Katılımcıların tümü lisans ve yüksek lisans öğrencisi olup 17-30 yaş aralığındadır ve sosyal medya hesaplarından en az bir fenomeni takip etmektedir. Sosyal medya mecraları arasında Instagram toplam 88 kişi tarafından ilk tercih edilen mecra seçilmiştir. İkinci en çok takip edilen mecra ise 80 kişiyle Youtube'dur. Üçüncü sırada ise 46 kişiyle Twitter gelmektedir. Facebook ve Snapchat de sirasıyla takip edilen diğer mecralar olmuştur. Erkek katılımcılar tarafından en çok takip edilen isimler, Orkun Işıtmak, Berkcan Güven ve Aykut Elmas iken, kadın katılımcıların en çok takip ettikleri isimler Danla Biliç, Yasemin Sakallıoğlu ve Gamze Erçel olmuştur.

\subsection{Doğrulayıcı Faktör Analizi (CFA)}

İlk olarak yapılan doğrulayıcı faktör analizi ile faktör yapısının geçerliliğinin doğrulanıp doğrulanmadığını görmek amacıyla uyum iyiliği değerlerine bakılmıştır. Tablo 1'de yer aldığ model uyum değerlerine bakıldığında elde edilen bulgular (CMIN/DF=2,628; CFI=0.909; RMSEA=0,09) sonucunda ölçek maddelerinin ilgili boyutlara kabul edilebilir bir uyum göstererek yüklendiği görülmüştür. 
Tablo 1. Doğrulayıcı Faktör Analizi Uyum İyiliği İstatistikleri

\begin{tabular}{|c|c|c|}
\hline Ölçüm & Eşik Değerler & $\begin{array}{c}\text { Elde } \\
\text { Edilen } \\
\text { Değerler }\end{array}$ \\
\hline $\begin{array}{l}\mathrm{X}^{2} \\
(\mathrm{CMIN} / \mathrm{sd})\end{array}$ & $\begin{array}{l}<3 \text { iyi; <5 kabul } \\
\text { edilebilir }\end{array}$ & 2.628 \\
\hline $\begin{array}{l}\text { Anlamlılık } \\
\text { değeri (p value) }\end{array}$ & $>0,05$ & 0.06 \\
\hline CFI & $\begin{array}{l}>0,95 \text { iyi; }>0,90 \\
\text { geleneksel, } \\
>0,80 \text { kabul } \\
\text { edilebilir }\end{array}$ & 0.90 \\
\hline RMSEA & $\begin{array}{l}<0,05 \text { iyi; } 0,05- \\
0,10 \text { orta; } \\
>0,10 \text { kötü }\end{array}$ & 0.09 \\
\hline
\end{tabular}

Tablo 2'de ise her bir faktörün yükü, her ölçekteki ifade sayısı ve ölçeklere ait Cronbach Alpha güvenilirlik değerleri gösterilmiştir.

Tablo 2. Doğrulayıcı Faktör Analizi (CFA)

\begin{tabular}{|c|c|c|c|}
\hline & St. Faktör & & \\
\hline Yap1 & Yükü & Güvenilirlik & İfade sayıs1 \\
\hline güven1 & 0.857 & 0.765 & 3 \\
\hline güven2 & 0.661 & & \\
\hline güven3 & 0.745 & & \\
\hline çekicilik1 & 0.799 & 0.788 & 4 \\
\hline çekicilik2 & 0.383 & & \\
\hline çekicilik3 & 0.763 & & \\
\hline çekicilik4 & 0.796 & & \\
\hline satınalma1 & 0.744 & 0.807 & 3 \\
\hline satınalma2 & 0.745 & & \\
\hline satınalma3 & 0.8 & & \\
\hline markatutumu1 & 0.96 & 0.936 & 3 \\
\hline markatutumu2 & 0.974 & & \\
\hline markatutumu3 & 0.789 & & \\
\hline uzmanlık1 & 0.662 & 0.754 & 3 \\
\hline uzmanlık2 & 0.803 & & \\
\hline uzmanlık3 & 0.664 & & \\
\hline
\end{tabular}

Kullanılan ölçeklerin geçerliliğini tespit etmek amacıyla yine doğrulayıcı faktör analizinden faydalanılmıştır. Yapılan yakınsama ve ayrım geçerliği analizinde ortalama açıklanan varyans (AVE) değerinin 0,50'nin ve yap1 güvenilirliği değerlerinin (CR) 0,70'in üzerinde olmas1 beklenmektedir (Fornell ve Larcker, 1981). Tablo 2'de de yer aldığ yap1 güvenirliği değeri (CR) 0,70 ve açıklanan varyans değerinin (AVE) 0,50'nin üzerinde olduğu görülmüş ve tüm değişkenlerin yakınsaklık geçerliliği kriterleri sağlanmıştır. Öte yandan Fornel ve Larcker (1981)'in yaklaşımıyla yapılan ayrım geçerliliği analizinde bir faktörün AVE karekökünün, bu faktörün değer faktörlere olan korelasyon değerinden büyük olması ve MSV değerinin AVE değerinden küçük olması gerekmektedir. Yapılan analiz sonucunda söz konusu ayrım geçerliliği şartları sağlanmış ve ilgili değerler Tablo 3 'te sunulmuştur.
Tablo 3. Geçerlilik Analizi

\begin{tabular}{|c|c|c|c|c|c|c|c|}
\hline & CR & $\begin{array}{l}\text { AV } \\
\text { E }\end{array}$ & $\begin{array}{l}\text { Tut } \\
\text { um }\end{array}$ & $\begin{array}{l}\text { Güvenil } \\
\text { irlik }\end{array}$ & $\begin{array}{l}\text { Çekic } \\
\text { ilik }\end{array}$ & $\begin{array}{l}\text { Satınal } \\
\text { ma }\end{array}$ & $\begin{array}{l}\text { Uzma } \\
\text { nlık }\end{array}$ \\
\hline & 0.9 & 0.8 & 0.81 & & & & \\
\hline Tutum & 36 & 31 & 2 & & & & \\
\hline Güvenil & 0.7 & 0.5 & 0.46 & & & & \\
\hline irlik & 65 & 25 & 9 & 0.524 & & & \\
\hline Çekicili & 0.7 & 0.7 & 0.51 & & & & \\
\hline $\mathrm{k}$ & 88 & 09 & 3 & 1.014 & 0.706 & & \\
\hline Satınal & 0.8 & 0.7 & 0.91 & & & & \\
\hline $\mathrm{ma}$ & 07 & 83 & 3 & 0.587 & 0.505 & 0.763 & \\
\hline Uzmanl1 & 0.7 & 0.5 & 0.15 & & & & \\
\hline $\mathrm{k}$ & 54 & 08 & 9 & 0.427 & 0.374 & 0.176 & 0.713 \\
\hline
\end{tabular}

\subsection{Hipotez Testleri}

Doğrulayıcı faktör analizi sonucunda elde edilen ölçüm modelinin kabul edilebilir uyum iyiliği istatistiklerini sağladığından, araştırma hipotezlerini test etmek için yapısal eşitlik modeli oluşturulmuştur. Model test edilirken SPSS AMOS programı kullanılmıştır. Yapısal eşitlik modelinin uyum indekslerine ilişkin değerleri Tablo 4'te yer almaktadır. Modelin uyum indekslerine ilişkin değerler incelendiğinde; CMIN/DF değerinin 2.097, GFI (Goodness of fit index) değerinin .959, AGFI (Düz. goodness of fit index) değerinin .90, CFI (Comperative fit indexKarşılaştırmalı uyum indeksi) değerinin .976ve RMSEA (Root mean square error of approximation-Kök ortalama kare yaklaşım hatası) değerinin 0.069 olduğu tespit edilmiştir. Sonuç olarak, elde edilen bu değerlere göre verilerin iyi uyum iyiliği değerleri ile kabul edilebilir değerler ortaya koyduğu ve oluşturulan yapısal eşitlik modelinin kabul edilebilir olduğu görülmektedir (Kline, 1998).

Tablo 4. Yapısal Eşitlik Modeli Uyum İyiliği İstatistikleri

\begin{tabular}{lccccc}
\hline & X2/df & CFI & GFI & AGFI & RMSEA \\
\hline $\begin{array}{l}\text { Uyum } \\
\text { Iyiliği }\end{array}$ & 2.097 &, 976 &, 959 &, 90 &, 069 \\
$\begin{array}{l}\text { Değerleri } \\
\text { Iyi }\end{array}$ & & & & & \\
$\begin{array}{l}\text { Uyum } \\
\begin{array}{l}\text { Değerleri } \\
\text { Kabul } \\
\text { Edilebilir }\end{array}\end{array}$ & $3<(\mathrm{x} 2 / \mathrm{df})<5$ & $>.90$ & $>.90$ & $>.90$ & $<.08$ \\
$\begin{array}{l}\text { Uyum } \\
\text { Değerleri }\end{array}$ & & & & & \\
\hline
\end{tabular}

Modelin yapısal olarak uygun olduğu belirlendikten sonra modelde yer alan ilişkilerin anlamlı olup olmadığını kontrol etmek amacıyla araştırma hipotezleri test edilmiştir. Analiz sonucunda elde edilen $\mathrm{p}$ değerleri Tablo 5 'te sunulmuştur. YEM sonuçlarına göre çekiciliğin marka tutumuna pozitif etkisi olduğu $(\beta=.37 ; p<.05)$ ancak satın almaya doğrudan etkisi olmadığ $1(\mathrm{p}>.05)$, güvenilirliğin hem marka tutumuna $(\beta=.18 ; p<.05)$ hem de satın alma niyetine $(\beta=.15 ; p<.05)$ pozitif etkisi olduğu, algısal homofilinin ise güvenilirliğe pozitif etkisi $\beta=.11 ; p<.05$ ) olduğu ancak marka tutumuna doğrudan etkisi olmadığ1 görülmüştür $(p>0.05)$. Uzmanlığın ise marka tutumuna da satın alma niyetine de etkisi görülmemiştir ( $\mathrm{p}>.05)$. Ek olarak, fenomenle marka arasındaki uyumun hem marka tutumuna $(\beta=.19 ; \mathrm{p}<.05)$ 
hem de satın alma niyetine $(\beta=.18 ; \mathrm{p}<.05)$ pozitif etki ettiği saptanmıştır. Bu nedenle marka tutumunun aracılık etkisi ayrıca Tablo 6'da yer verildiği üzere aracılık analizi ile incelenmiştir. Son olarak, marka tutumunun satın alma niyeti üzerinde güçlü pozitif etkisi olduğu onanmıştır $(\beta=.71 ; \mathrm{p}<.05)$. Böylece, H1a, H2a, H2b, H4b, H5a, H5b ve H6 hipotezleri kabul edilmiştir.

Tablo 5. Hipotez Testleri

\begin{tabular}{|c|c|c|}
\hline Hipotez & $\begin{array}{c}\text { Standardize } \\
\text { Regresyon } \\
\text { Katsay1s1 }\end{array}$ & $\underset{\text { değeri }}{\mathrm{p}}$ \\
\hline $\begin{array}{l}\text { H1a: Çekicilik--> Marka } \\
\text { tutumu }\end{array}$ & 0.375 & $* *$ \\
\hline $\begin{array}{l}\text { H1b: Çekicilik--> Satın alma } \\
\text { niyeti }\end{array}$ & & $\mathrm{p}>0.05$ \\
\hline $\begin{array}{l}\text { H2a:Güvenilirlik--> Marka } \\
\text { tutumu }\end{array}$ & 0.176 & $* *$ \\
\hline $\begin{array}{l}\text { H2b:Güvenilirlik--> Satın } \\
\text { alma niyeti }\end{array}$ & 0.148 & $* *$ \\
\hline $\begin{array}{l}\text { H3a:Uzmanlık--> Marka } \\
\text { tutumu }\end{array}$ & & $\mathrm{p}>0.05$ \\
\hline $\begin{array}{l}\text { H3b:Uzmanlık-->Satın alma } \\
\text { niyeti } \\
\text { H4a Algisal homofili--> }\end{array}$ & & $\mathrm{p}>0.05$ \\
\hline Marka tutumu & & $\mathrm{p}>0.05$ \\
\hline $\begin{array}{l}\text { H4b Algisal homofili --> } \\
\text { Güvenilirlik }\end{array}$ & 0.108 & $* *$ \\
\hline $\begin{array}{l}\text { H5a: Fenomenle marka } \\
\text { arasindaki uyum--> Marka } \\
\text { tutumu }\end{array}$ & 0.186 & $* *$ \\
\hline $\begin{array}{l}\text { H5b: Fenomenle marka } \\
\text { arasındaki uyum --> Satın } \\
\text { alma niyeti }\end{array}$ & 0.181 & $* * *$ \\
\hline $\begin{array}{l}\text { H6: Marka tutumu--> Satın } \\
\text { alma niyeti }\end{array}$ & 0.71 & $* * *$ \\
\hline
\end{tabular}

\subsection{Marka Tutumunun Aracılık Etkisine İlişkin Analiz}

Marka tutumunun fenomen-marka uyumu ile satın alma niyeti arasındaki ilişkideki aracılık rolünü araştırmak amacıyla H7 hipotezi oluşturulmuştur. AMOS yapısal eşitlik modeli analizinde Bootstrap yöntemi kullanılmış, aracılık etkisi olmadan ve aracı değişken etkisiyle $\mathrm{R}^{2}$ değerleri ölçülmüştür. Her iki modelde anlamlı olmakla beraber, aracı değişkenin etkisiyle 0.31 'den 0.18 'e düşmüştür ve marka tutumunun, fenomen-marka uyumu ile satın alma niyeti ilişkisinde aracılık etkisi olduğu doğrulanmıştır (Tablo 6).

Tablo 6. Marka Tutumunun Arac1lık Etkisi

\begin{tabular}{llll}
\hline & $\begin{array}{l}\text { Doğrudan } \\
\text { etki }\end{array}$ & $\begin{array}{l}\text { Aracı } \\
\text { değişken } \\
\text { ile etki }\end{array}$ & $\begin{array}{l}\text { Dolaylı } \\
\text { etki }\end{array}$ \\
Hipotez & & $\begin{array}{l}\mathrm{R}^{2}= \\
\text { Marka-fenomen uyumu-- }\end{array}$ & \\
$>$ Marka tutumu --> Satın & $\mathrm{R}^{2}=0.31$ & $0.18(\mathrm{p}$ & K1smi \\
alma niyeti & $(\mathrm{p}<0.05)$ & $<0.05)$ & aracılık \\
\hline
\end{tabular}

\section{Sonuc}

Sosyal medya reklamcılığının yeni bir biçimi olan fenomen pazarlaması son yıllarda literatürde yer almaya başlamıştır. Sosyal medya fenomenleri, sosyal medyanın fikir liderleri olarak tanımlanır ve "bir veya birkaç alanda güvenilir destekçiler" olarak kabul edilirler (DeVeirman vd., 2017: 798). Bu çalışmada, günümüzde önemli bir dijital pazarlama aracı olarak görülen marka fenomenlerinin, tüketicinin markaya karşı tutumunu ve satın alma niyetini etkilemedeki rolü incelenmiştir. Bu amaçla, fenomenlerin güvenilirliği, çekiciliği, uzmanlığı, takipçinin fenomene karşı homofili algısı ve marka-fenomen uyumu değişkenleri çerçevesinde konu analiz edilmiştir.

124 takipçiden elde edilen verilerle gerçekleştirilen araştırmanın bulgularına göre, algısal homofili diğer bir deyişle takipçilerin marka fenomeni ile kendini demografik ve sosyal açıdan benzetme düzeyinin, fenomene duyduğu güven ile paralel olduğu görülmüştür. Fenomen kişiyi kendine fiziken, ruhen, davranış biçimi veya üyesi olduğu sosyal sınıf açısından benzetiyor olması o kişinin önerilerine daha çok güven duymasına yol açmaktadır. Tanıtımı yapılan (desteklenen) markaya karşı olumlu bir tutum oluşturmada, fenomene duyulan güven, fenomenin çekiciliği ve fenomenin konu ile ilgili uzmanlığının etkisi ölçüldüğünde, değişkenlerin sadece ikisinin etkili olduğu görülmüştür. Fenomen çekiciliğinin markaya karşı olumlu tutum geliştirmedeki rolü Swant'ın (2016) Twitter kullanıcıları ile yaptığı çalışmada da ortaya konmuştur. Takipçilerin, fenomene duyduğu güven düzeyi ve fenomeni çekici bulma düzeyi yükseldikçe desteklediği markaya karşı olumlu tutum takınmaktadır. Bahsedilen çekicilik sadece fiziksel güzelliği ifade etmemekte, kişinin genel özellikleri ve tutumu bakımından beğenilme düzeyini de ifade etmektedir. Kahle ve Homer'in (1985) kanaat liderleri üzerinde yapmış olduğu çalışmaların sonuçları Instagram fenomenleri için de doğrulanmıştır. Kanaat liderleri için marka tutumu yaratmakta uzmanlık derecesi önemli bir faktör iken, fenomenlerin marka tutumuna olan katkısını inceleyen çalışmada fenomenin konu ile ilgili uzmanlık derecesinin markaya karşı olumlu tutum oluşturmada da, markayı satın alma eğilimini artırmada da bir etkisinin olmadığı görülmüştür. Öte yandan Erdoğan'ın (1999) çalışmasında ise fenomenin uzmanlığının da, fenomen kullanımının marka açısından etkililiği artırdığı yönünde bulgulara rastlanmıştır.

Fenomenin özelliklerinden sadece fenomene duyulan güvenin marka tutumunun yanı sıra satın alma niyetine de doğrudan etki ettiği tespit edilen bir diğer husustur. Ek olarak tutumların davranışlara neden olduğunu ileri süren Gerekçeli Aksiyonlar Teorisi (TRA) ile paralel olarak, marka tutumunun markayı satın alma niyeti üzerinde olumlu etkisi olduğu doğrulanmıştır. Fenomenle, desteklenen marka arasındaki uyum ise araştırmada ele alınan bir diğer değişkendir. Fenomen kişinin özelliklerinin marka kişiliğiyle uyumlu olması, marka tutumunu pozitif etkilediği gibi satın alma niyetine de olumlu katkı yaptığı görülmektedir. Söz konusu bulgu önceki çalışmaların sonuçları ile tutarlıdır (Torres vd., 2019; Breves vd., 2019).

Marka yöneticilerinin fenomen pazarlamasindan yararlanmak istemeleri durumunda, fenomen seçimleri pazarlama çabalarının başarısında kritik rol oynamaktadır. Öncelikle seçilen kişinin yaşam tarzının marka dinamikleri 
ile örtüşmesi, markanın değer sistemi ile ters düşmemesi, marka kişiliğiyle fenomen kişiliğinin benzer olması ilk dikkat edilmesi gereken noktadır. Markayı temsil etme yetisine sahip olduğu düşünülen bir fenomen seçildikten sonra, kişinin halk tarafından güvenilir bulunuyor olması bir diğer önemli faktördür. Kişinin özel ve meslek hayatında sözünün eri olarak bilinmesi desteklediği markayla ilgili kullandığı argümanlarda da samimi ve gerçekçi olduğunu düşündürmektedir. $\mathrm{Bu}$ sebeple markalar her sene ölçülen sanatçı güven indeksinden yararlanarak kamu gözünde ünlülerin ne kadar güvenilir bulundukları konusunda görüş sahibi olmalıdır. Marka tutumuna pozitif etki eden diğer bir özellik olan fenomen çekiciliği, fiziksel markayı yansıtacak kişinin fiziksel güzelliği, karizması, hal ve tavırları ile beğeni uyandırması veya imrenilen bir kişi olmasını ifade etmektedir. Tanıtımı yapılan ürünün içinde olduğu sektöre göre bu özelliklerden biri ya da birkaçı ön plana çıkabilir. Bir kozmetik markası, fenomene kişi olarak güzellik kraliçesi ile çalışarak kişinin var olan doğal güzelliğini markasına reflektör olarak kullanmayı tercih ederken, bir beyaz eşya markası çekici bir fenomen olarak başarılı ve tanınmış bir aşçıdan yararlanabilmektedir. Fenomen güvenilirliğine doğrudan, marka tutumuna dolaylı olarak etki eden algısal homofili, takipçilerin marka fenomeni ile kendilerini benzetme oranları pazarlama profesyonellerinin üzerinde durması gereken bir diğer önemli noktadır. Ürün veya hizmetleri doğru kitleye doğru şekilde pazarlayabilmek için kullanılan segmentlere ayırma, hedefleme ve konumlandirma (STP) stratejileri vasitasıyla markalar, kullanıcılarını ve potansiyel kullanıcılarını segmentlere ayırarak, hangi hedef kitleye markasını ne şekilde konumlandıracağına karar verirken, fenomen seçiminin hangi hedef kitleye uygun olacağı, hangi hedef kitle ile benzeştiğini de dikkate almalıdır. Bir spor salonu, hedef kitlesini, ağırlıklı olarak formda kalmak isteyen kadınlardan ve vücut geliştirmek isteyen genç erkeklerden oluşturabilir. Ancak her iki hedef kitle için farklı konumlandırma yapması gerektiği gibi, fark1 fenomenlerden yararlanması söz konusu olacaktır. İlk grup için halk tarafından sevilen bir anne figürü hedef kitleyle daha çok benzeşim yakalarken, ikinci grup için bir basketbolcu daha dikkat çekici olacaktır. Bu sonuçlar, markaların birden fazla fenomenle çalışmalarının ne şekilde sonuçlanacağı konusunda da merak uyandırmaktadır. Söz konusu fenomenlerin ne süreyle marka fenomeni olarak çalışmaya devam etmesi gerektiği, ürün yaşam eğrisine paralel olarak mı yoksa daha kısa dönemli bir ortaklık mı marka için uygun olacaktır gibi sorular bu alanda gerçekleştirilecek diğer akademik çalışmalar için araştırma konusu önerisi olarak sunulabilir. Takipçi sayısına göre mikro ve makro ünlüler olarak sınıflandırılan fenomen gruplarından hangileri ile çalışmak marka için daha avantajlı olur, pandemi esnasında fenomen pazarlaması ne yönde ilerledi, kişisel verilerin korunması konusundaki düzenlemeler fenomen pazarlamasını ne şekilde etkileyecek (Haenlein vd.,2020) gibi araştırma konuları da bu listeye eklenebilir.

\section{Kaynakça}

Amos, C., G. Holmes ve D. Strutton (2008), "Exploring The Relationship Between Celebrity Endorser Effects And Advertising Effectiveness: A Quantitative Synthesis Of Effect Size.” International Journal Of Advertising 27, 2 : 209-234.

Banister, E. N. ve Cocker, H. L (2014), A Cultural Exploration Of Consumers' Interactions And Relationships With Celebrities. Journal Of Marketing Management, 30(1-2), 1-29.

Baruönü, F.Ö. (2019), Pazarlamada Dijital Dönüşüm. Prof. Dr. Muazzez Babacan (Ed.) Dijital Dönüşüm Ekseninde İşletme Uygulamaları. Detay Yayınları. İstanbul:Türkiye.

Bergkvist, L., Hjalmarson, H., ve Mägi, A. W. (2016), A New Model Of How Celebrity Endorsements Work: Attitude Toward The Endorsement As A Mediator Of Celebrity Source And Endorsement Effects. International Journal Of Advertising, 35, 171-184.

Bevilacqua, Jessica ve Del Giudice Elizabeth (2018), "Why Brands Need To Utilize Influencer Marketing İn 2018," St. Joseph Communications, April 3, Https:/Stjoseph.Com/ İnsight/İnfluencerMarketing-2018-İnfographic/, Erişim Tarihi 3 Mart 2020

Breves, P. L., Liebers, N., ve Abt, M. (2019). The Perceived Fit Between Instagram Influencers And The Endorsed Brand How Influencer - Brand Fit Affects Source Credibility And Persuasive Effectiveness, (December), 440-455.

Chai, J. C. Y., Malhotra, N. K., ve Alpert, F. (2015) “A Two-Dimensional Model Of Trust-Value-Loyalty In Service Relationships". Journal Of Retailing And Consumer Services, 26, 23 -31.

Choi, S. M., ve Rifon, N. J. (2012) "It Is A Match: The Impact Of Congruence Between The Celebrity Image And Consumer İdeal Self On Endorsement Effectiveness". Psychology Ve Marketing, 29, 639650 .

Chung, S., ve Cho, H. (2017) "Fostering Parasocial Relationships With Celebrities On Social Media: Implications For Celebrity Endorsement". Psychology Ve Marketing, 34(4), 481-495.

Colliander, J., ve Dahlén, M. (2011) "Following The Fashionable Friend: The Power Of Social Media: Weighing Publicity Effectiveness Of Blogs Versus Online Magazines". Journal Of Advertising Research, 51, 313-320.

Crisci, R. ve Kassinove H.,(1973) "Effects Of Perceived Expertise, Strength Of Advice, And Environmental Setting On Parental Compliance," The Journal Of Social Psychology. 89 (2), 245-250.

Crutchfield, D. (2010) "Celebrity Endorsements Still Push Product”. Http://Adage/Article/Cmo-Strategy/ Marketing-Celebrity-Endorsements-PushProduct/146023/,Erişim Tarihi 12.03.2020 
Curalate. (2016, July 27). "Influencer Marketing: The Good, The Bad And The Downright Ugly." Https://Www.Curalate.Com/Blog/ İnfluencerMarketing-Fails/ Erişim Tarihi 11.02.2020

Dean, D. H., ve Biswas, A. (2001). "Third -Party Organization Endorsement Of Products: An Advertising Cue Affecting Consumer Prepurchase Evaluation Of Goods And Services". Journal of Advertising, 30(4), 41-57.

De Veirman, M., Cauberghe, V. ve Hudders, L. (2017), "Marketing Through Instagram Influencers: The Impact Of Number Of Followers And Product Divergence On Brand Attitude," International Journal Of Advertising, 36 (5), 798-28.

Djafarova, E. ve Rushworth, C (2017), "Exploring The Credibility Of Online Celebrities' Instagram Profiles In Influencing The Purchase Decisions Of Young Female Users," Computers In Human Behavior, 68 (March), 1-7

Erdogan, B. Z. "Celebrity Endorsement: A Literature Review." Journal Of Marketing Management 15, 4 (1999): 291-314.

Evans, N. , J. Phua, J., Lim, J. ve Jun, H.. "Disclosing Instagram Influencer Advertising: The Effects Of Disclosure Language On Advertising Recognition, Attitudes, And Behavioral Intent." Journal of Interactive Advertising 17, 2 (2017): 138-149.

Everett, M. R., Bhowmik, D. (1971), "HomophilyHeterophily: Relational Concepts For Communication Research", Public Opinion Quarterly, 34, 523-538

Fleck, N., Korchı, M.,ve Le Roy, I. (2012).”Celebrities İnadvertising: Looking For Congruence Or Likability?” Psychology Ve Marketing, 29, 651 -662

Friedman, H. H., ve L. Friedman. "Endorser Effectiveness By Product Type.” Journal Of Advertising Research 19, 5 (1979): 63-71.

Fornell, C., ve Larcker, D. F. (1981). "Evaluating Structural Equation Models With Unobservable Variables And Measurement Error", Journal Of Marketing Research, 3950.

Giffin, K. (1967), "The Contribution Of Studies Of Source Credibility To A Theory Of Interpersonal Trust İn The Communication Process," Psychological Bulletin, 68 (2), 104-119.

Gilly, M. C., Graham, J. L., Wolfinbarger, M. F. ve Yale, L. J. (1998), "A Dyadic Study Of İnterpersonal Information Search", Journal Of The Academy of Marketing Science. 26, 2, 83-100

Horai, J.M., Naccarii, N. ve Fatouuah, E. (1974), "The Effects Of Expertise And Physical Attractiveness Upon Opinion Agreement And Liking," Sociomeity, 37 (4), 601606.

Hovland, C. I., Irving K. J, ve Kelley, H. (1953), Communication And Persuasion, New Haven, Ct: Yale University Press.
Kahle, L. R. ve Homer, P.M. (1985), "Physical Attractiveness Of The Celebrity Endorser: A Social Adaptation Perspective," Journal Of Consumer Research, 11 (March), 954-961.

Kamıns, M. A. (1990). "An Investigation Into The "MatchUp" Hypothesis In Celebrity Advertising: When Beauty May Be Only Skin Deep". Journal Of Advertising , 19,4-13.

Kamins, M. A., \& Gupta, K. (1994). “Congruence between spokesperson and product type: A matchup hypothesis perspective". Psychology \& Marketing, 11(6), 569-586

Katz, E., Lazarsfeld, P.F. (1955), Personal Influence, Free Press, Glencoe, I

Kline, R.B. (1998). Principles And Practice Of Structural Equation Modeling, The Guilford Pres, New York.

Koernig, S. K., ve Boyd, T.C. (2009). "To Catch A Tiger Or Let Him Go: The Match-Up Effect And Athlete Endorsers For Sport And Non-Sport Brands." Sport Marketing Quarterly 18 (2009): 25-37.

Lazarsfeld, P., Merton, R. (1954), Friendship As A Social Process: Asubstantive And Methodological Analysis. Içinde Ed. Monroe Berger, Theodore Abel, And Charles $\mathrm{H}$ (Freedomand Control İn Modern Society New York: Van Nostrand, 18-66 Miller Ve Baseheart (1969)

Lester, L., Lester, L., Edwards, P., Fleming, A., Lacey, J., Lester, L., ... Williams, T. (2019). Trust , Engagement, İnformation And Social Licence Insights From New Zealand Trust, Engagement, İnformation And Social Licence - İnsights From New Zealand.

Linq1a. (2018). "The State Of Influencer Marketing 2018." Retrieved March 9, 2018, From Http://Www.Linqia.Com/İnsights/Report-TheState-Of-İnfluencermarketing-2018/, Erişim Tarihi 15.12.2019

Lou, C., ve Yuan, S. (2019). "Influencer Marketing : How Message Value And Credibility Affect Consumer Trust Of Branded Content On Social Media Influencer Marketing: How Message Value And Credibility Affect Consumer". Journal of Interactive Advertising, 0(0), 1-16.

Maddux, James E. ve Rogers, R.W. (1980), "Effects Of Source Expertness, Physical Attractiveness And Supporting Arguments On Persuasion: A Case Of Brains Over Beauty," Journal Of Personality And Social Psychology, 39 (2), 235-244.

Mccracken, G. "Who Is The Celebrity Endorser? Cultural Foundations Of The Endorsement Process." Journal Of Consumer Research 16, 3 (1989): 310-321.

Mcquall, D. (1983), Mass Communication Theory: An Introduction, London: Sage.

Miller, F. M., ve Lacznıak, G. R. (2011). "The Ethics Of Celebrity-Athlete Endorsement: What Happens When A Star Steps Out Of Bounds?" Journal Of Advertising Research, 51(3), 499-510. 
Mills, J. ve Aronson, E. (1965), "Opinion Change As A Function Of Communicator's Attractiveness And Desire To Influence," Journal Of Personality And Social Psychology, 1 (2), 173-177.

Mills, J. ve Harvey, J. (1972), "Opinion Change As A Function Of When Information About The Communicator İs Received And Whether He İs Attractive Or Expert," Journal Of Personality And Social Psychology, 21 (1), 52-55.

Mishra, A. S, Roy,S. ve Bailey, A.A. (2015) "Exploring Brand Personality- Celebrity Endorser Personality Congruence İn Celebrity Endorsements İn The Indian Context." Psychology \& Marketing 32, 12 1158-1174.

Nguyen, B., Choudhury, M. M., ve Melewar, T. C. (2015). "An Integrated Model Of Firms' Brand Likeability: Antecedents And Consequences". Journal Of Strategic Marketing, 23, 122-140.

Ohanian, R. (1990). Construction And Validation Of A Scale To Measure Celebrity Endorsers ' Perceived Expertise , Trustworthiness , And Attractiveness, Journal Of Advertising, 19(3), 39-52.

Örs, M. (2018). “İnternet Fenomenlerini Neden Takip Ediyoruz? Tüketici-Fenomen İlişkisini Güçlendiren Nedenlerin Ampirik Bir Çalışma İle Değerlendirilmesi”, İşletme Araştırmaları Dergisi, 10 (4), 187-209.

Patel, D. "10 Tips For Marketing To Gen Z Customers", Forbes,

Https://Www.Forbes.Com/Sites/Deeppatel/2017/05 /01/10-Tips-For-Marketing-To-Gen-Z-

Consumers/\#36fabae43c50, Erişim Tarihi 10.01 .2020

Reeves, R. A., Baker, G. A., ve Truluck, C. S. (2012). "Celebrity Worship, Compulsive Buying, And The Empty Self”. Psychology \& Marketing, 29(9), 674679.

Sakib, M. N., Zolfagharian, M. ve Yazdanparast, A. (2019). "Does Parasocial İnteraction With Weight Loss Vloggers Affect Compliance? The Role Of Vlogger Characteristics, Consumer Readiness, And Health Consciousness". Journal Of Retailing And Consumer Services.

Senft, T. (2008). Camgirls: Celebrity And Community In The Age Of Social Networks. New York: Peter Lang.
Sipahi, B. (2010), Sosyal Bilimlerde SPSS'le Veri Analizi, Beta Yayınları, İstanbul.

Spitzberg, B. H., ve Cupach, W. R. (2008). "Fanning The Flames Of Fandom: Celebrity Worship, Parasocial İnteraction, And Stalking”. In J. R. Meloy, L. Sheridan, Ve J. Hoffman (Eds.), Stalking, Threatening, And Attacking Public Figures: A Psychological And Behavioral Analysis (Pp. 287321). New York, Ny: Oxford University Press.

Steadman, M. (1969), "How Sexy Illustrations Affect Brand Recall," Journal of Advertising Research, 9 (February), 15-19

Swant, M. (2016), "Twitter Says Users Now Trust Influencers Nearly As Much As Their Friends," Adweek, May 10, Http://Www.Adweek.Com/Digital/TwitterSaysusers-Now-Trust-İnfluencers-Nearly-MuchTheir-Friends171367/, Erişim Tarihi 02.01.2020

Tabachnick, B.\& Fidell, L.S.. (2007). Using Multivarite Statistics. Pearson Education,USA.

Till, B. D., Ve Busler, M. (1998). "Matching Products With Endorsers: Attractiveness Versus Expertise". Journal Of Consumer Marketing, 15(6), 576-586.

Torres, P., Augusto, M.,ve Matos, M. (2019). "Antecedents And Outcomes Of Digital Influencer Endorsement : An Exploratory Study", Psychology \& Marketing, 36(12), 1267-1276.

Tran, G. A., ve Strutton, D. (2014). "Has Reality Television Come Of Age As A Promotional Platform? Modeling The Endorsement Effectiveness Of Celebreality and Reality Stars". Psychology \& Marketing, 31(4), 294-305.

Tran, G. A., ve Strutton, D. (2019). "Investigating The Marketing Impact Of Consumers ' Connectedness To Celebrity Endorsers". Psychology \& Marketing 36 (10), 923-935

Weimann G., (1994), The Influentials: People Who Influence People, State University Of New York Press, Albany, Ny

Wolfinbarger, M.F., Gilly, M.C. (1993). The Encoding And Decoding Of Gift Symbolism, University Of California At Irvine Working Paper 


\section{Extended Abstract}

Social media influencers are defined as the opinion leaders on social media, and they are considered as reliable supporters in one or more fields. Getting a large number of followers on social media by creating content on Youtube, Instagram and Twitter permanently makes them even more popular than traditional celebrities such as singers, actors, or models (Patel, 2019). It is known that 39\% of marketers increase their budgets for influencer marketing and $19 \%$ spend more than $\$ 100,000$ per campaign.

Influencer marketing is based on two general theories; the source reliability model and the resource attraction model. The source reliability model defines reliability, attractiveness, and expertise as the basic dimensions of reliability (Amos et al., 2008; Ohanian, 1990). The origins of the resource attraction model stem from social and psychological research and is a component of McGuire's "resource valence" model (McGuire, 1985). The attractiveness model claims that the effectiveness of a message depends on the "familiarity", "similarity", and "attractiveness" of the source to the participants. The mentioned attractiveness does not only mean the attractiveness of physical properties but also elegance (Mills \& Aronson, 1965), and sexuality (Steadman, 1969). Tran et al. (2019) tried to explain how influencers lead consumers to positive attitudes and behavioral responses within the scope of parasocial relationship theory. Parasocial relationship refers to the one-sided interpersonal relationships individuals establish with celebrities in the media (Sakib et al., 2019). Consumers are expected to be more affected by the products recommended by celebrities with whom they develop parasocial relationships (Chung \& Cho, 2017; Tran \& Strutton, 2014). The fact that social media makes consumer-phenomenon communication bidirectional with features such as liking, asking questions, and writing comments give parasocial relations a different meaning than traditional media. The relationship moves away from being wholly unidirectional and extends from brand to consumer, from influencer to consumer.

Perceptual homophilia is "how compatible two individuals are with each other, generally their demographic characteristics" but at the same time, homophilia coincides with perceptual similarities in variables such as values, preferences, and lifestyle (Everett and Bhowmik, 1971: 523-538). ) Studies show that consumers seek advice from similar-close sources and, in some cases, homophilic sources work better in seeking advice than expert sources (Gilly et al., 1998).

Based on the principle of matching between the celebrity and the brand, the person is expected to be a person who defines the brand and whose personality coincides with the brand personality (Bergkvist et al., 2016, Kamins, 1990; Choi \& Rifon, 2012; Fleck et al., 2012). The success of these pairings depends on marketers strategically identifying "right influencer" to ensure "right fit" (Kamins \& Gupta, 1994). Mishra, Roy, and Bailey (2015) utilized social adaptation theory and attribution theories to support this adaptation. In the context of social cohesion theory, it is based on the prediction that if celebrities' personalities seem appropriate to the promoted brand image, followers will perceive them as a useful source of information (Kamins, 1990; Mishra et al., 2015).
In this study, a conceptual model that demonstrates the influential factors in creating a positive consumer attitude and purchasing intention regarding the brands supported by social media influencers is proposed and tested with an empirical study. In May 2020, an online survey was conducted with 124 participants. It is known that university students generally rely on celebrities to improve their identity and appearance (Banister \& Cocker, 2014). For this reason, the sample of the study consisted of 124 undergraduate/graduate students between the ages of 18-30, who followed at least one phenomenon.

According to the findings of the study conducted with data obtained from 124 followers, the perceptual homophilia is directly related to their trust in influencer. The fact that the. When the effect of the trust in the influencer, the attractiveness of the influencer, and the expertise of the influencer on the subject were measured in forming a positive attitude towards the promoted brand, it was seen that only the trust and attractiveness dimensions were effective. As the level of trust of followers and the level of influencer attractiveness increase, they adopt a positive attitude towards the brand they support. It is also determined that the trust in influencer has a direct impact on the purchase intention and the brand attitude. Besides, in line with the Reasoned Actions Theory (TRA), which suggests that attitudes cause behavior, it has been confirmed that brand attitude has a positive effect on buying the brand. It is seen that the compatibility of the characteristics of the influencer with the brand personality positively affects the brand attitude and also contributes to the purchase intention of the customer. 